\title{
A simple method for determining the true specific fracture energy of concrete
}

\author{
B. L. Karihaloo, ${ }^{*}$ H. M. Abdalla* and T. Imjai* \\ Cardiff University
}

In a recent paper, Abdalla and Karihaloo confirmed the boundary effect hypothesis of Hu and Wittmann and observed that a size-independent specific fracture energy $G_{\mathrm{F}}$ of concrete could be obtained by testing three point bend (TPB) or wedge splitting (WS) specimens containing either a very shallow or a deep starter notch. This observation was based on TPB and WS tests on limited number of specimens. In this paper, we have re-evaluated 26 test data sets on specific fracture energy of concrete published in the literature to assess the validity of this observation. The re-evaluation is found to support this observation. The determination of the true specific fracture energy $G_{\mathrm{F}}$ of concrete thus becomes a simple and straightforward task requiring very few specimens of the same dimensions and shape. This re-evaluation also provides guidance for the selection of the specimen dimensions depending on the maximum size of aggregate used in the concrete mix in order to obtain its true $G_{\mathrm{F}}$

\section{Introduction}

The true specific fracture energy of concrete $G_{F}$ is the most useful material parameter in the analysis of cracked concrete structures. ${ }^{1}$ The test method for the determination of $G_{F}$ and even its precise definition has been a subject of intense debate among researchers because it has been found to vary with the size and shape of the test specimen and with the test method used. Guinea et $a l^{2}{ }^{2}$ identified several sources of energy dissipation that may influence the measurement of $G_{F}$, of which the curtailment of the tail part of the loaddeformation diagram in a test is the most important. ${ }^{3}$

$\mathrm{Hu}$ and Wittmann ${ }^{4}$ also addressed the issue of the curtailment of the load-deflection plot when the load tends to zero, i.e. the growing crack approaches the free surface of the test specimen. In a series of papers, 5,6 they argued that the effect of the free boundary is felt in the fracture process zone (FPZ) so that the energy required to create a fresh crack decreases as the crack grows. Initially, when the crack grows from a pre-existing notch, the rate of decrease is moderate but it accelerates as the crack approaches the free boundary

\footnotetext{
* School of Engineering, Cardiff University, Queen's Buildings, PO Box 925, Cardiff CF24 0YF, UK.

(MCR 1117) Paper received 21 February 2003; last revised 7 April 2003; accepted 22 May 2003
}

(Fig. 1). Therefore, they represented the change in the specific fracture energy by a bi-linear approximation, as shown in Fig. 1. The transition from the moderate to the rapid decrease occurs at the so-called transition ligament length ${ }^{7}$ that depends on the both the material properties and specimen size and shape. In general the

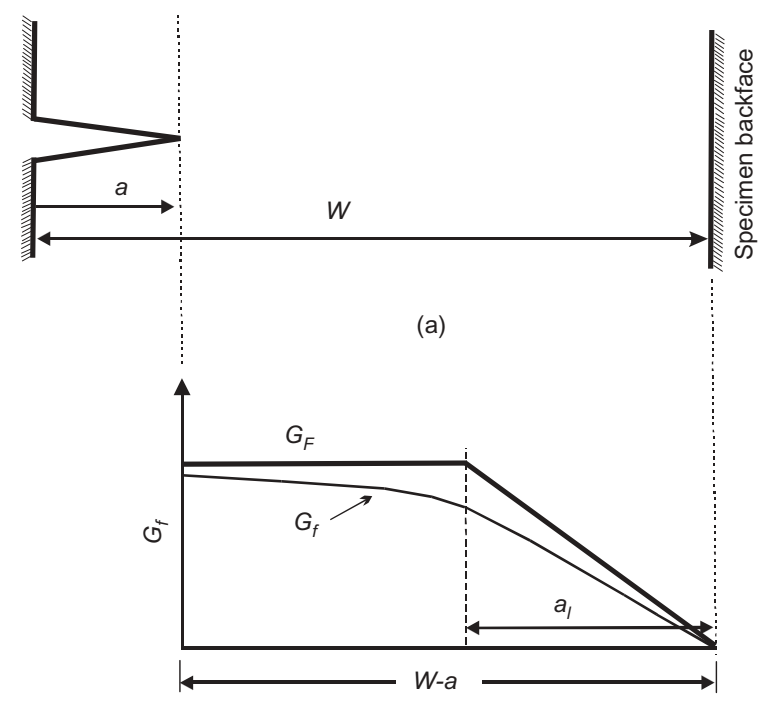

Fig. 1. A notched test specimen of depth $\mathrm{W}$ and notch depth $\mathrm{a}$ (a) showing the distribution of specific fracture energy $\left(\mathrm{G}_{\mathrm{f}}\right)$ along the un-notched ligament, $\mathrm{W}-\mathrm{a}$ (b) 
transition ligament length $a_{l}$ is smaller than the unnotched specimen ligament $(W-a)$. On the basis of the bi-linear approximation, the size-independent specific fracture energy $G_{F}$ can be back calculated from the measured specific fracture energy $G_{f}(a / W)$ from

$$
\begin{aligned}
& G_{f}(a / W)= \\
& \begin{cases}G_{f}\left[1-\frac{a_{1} / W}{2(1-a / W)}\right] ; & 1-a / W>a_{l} / W \\
G_{f} \cdot \frac{(1-a / W)}{2\left(a_{l} / W\right)} ; & 1-a / W \leqslant a_{l} / W\end{cases}
\end{aligned}
$$

Duan et $a .^{5,6}$ used the test results for $G_{f}(a / W)$ from the three point bend (TPB) tests conducted by Nallathambi et $a l^{8-10}$ It is customary to test specimens of varying size $W$ and several notch to depth ratios $a / W$, but to keep the span to depth ratio of TPB specimens constant. The number of the measured $G_{f}(a / W)$ values is therefore much larger than the two unknowns $G_{F}$ and $a_{l}$ in equation (1). For this reason the overdetermined system of equations is solved by a least squares method to obtain the best estimates of $G_{F}$ and $a_{l}$. Duan et $a l .{ }^{5,6}$ showed that although the measured values $G_{f}(a / W)$ depend strongly on $W$ and $a / W$ the above procedure indeed leads to a $G_{F}$ value that is essentially independent of the specimen size $W$ and geometry $a / W$, provided the span to depth ratio is constant.

This was confirmed by independent TPB and wedge splitting (WS) test results on three different mixes by Abdalla and Karihaloo. ${ }^{11}$ In the process of analysing the measured $G_{f}(a / W)$ values as per the free boundary effect model, they observed that the $G_{F}$ value of each of the three concrete mixes could also be obtained from just two mean values of $G_{f}(a / W)$ measured on specimens of any size $W$ and shape, provided the notch to depth ratios $a / W$ were well separated and not close to each other. If this observation were confirmed on a large body of independent test results, then the determination of the true specific fracture energy of concrete $G_{F}$ would be a simple and straightforward task. It would require testing of just a few specimens of any one overall size and shape with two notch to depth ratios and the solution of two simultaneous equations (1) in two unknowns $G_{F}$ and $a_{l}$ using the mean values of $G_{f}(a / W)$ for the two $a / W$ values. This would not only eliminate the use of least squares method for the solution of an overdetermined system of simultaneous equations but, more importantly, eliminate the time consuming and often cumbersome (when large specimens are required for testing) testing of a large number of specimens with different $W$ and $a / W$.

It is the aim of the present paper to re-evaluate the test data on measured specific fracture energy of concrete mixes available in published and/or easily accessible literature with a view to assessing the validity of the above observation. This re-evaluation confirms the observation made by Abdalla and Karihaloo ${ }^{11}$ and paves the way for a simple and practical means of determining $G_{F}$ of concrete. It also provides guidance for the selection of the specimen dimensions based on the maximum size of the coarse aggregate used in the concrete mix in order to obtain its $G_{F}$ that is truly independent of the shape and size of the test specimen.

\section{Re-evaluation of existing $G_{f}(a / W)$ data}

There is a large body of test data on the specific fracture energy of concrete available in published and/ or easily accessible literature. In almost all cases, the specific fracture energy $G_{f}(a / W)$ was calculated according to the RILEM recommendation ${ }^{12}$ as the average energy obtained by dividing the total work of fracture by the projected fractured area (i.e. the area of initially unnotched ligament of the specimen). In the two most commonly used test specimen geometries, TPB and WS (Fig. 2), the total work of fracture is the area under the load-central deflection diagram or the load-crack mouth opening diagram and the projected fractured area is ( $W-a) B$ (see Fig. 2).

Of this large body of available test data, a substantial proportion is unusable for the present purposes, because it pertains to a single $a / W$ ratio $(=0 \cdot 5)$, albeit for different size specimens. This single to depth ratio was recommended in the RILEM report ${ }^{12}$ based on the data collected during a round-robin testing programme. ${ }^{13}$

For the present work, it has been possible to gather 26 data sets obtained from TPB tests on different concrete mixes, ${ }^{14,15}$ excluding the 10 data sets on which the original observation of Abdalla and Karihaloo ${ }^{11}$ was based. Each data set includes $G_{f}(a / W)$ values measured on TPB specimens of the same depth $W$ but containing different starter notches, i.e. variable $\alpha=a$ / $W$ ratio. These 26 data sets are listed in the Appendix. Each set is provided with details of the specimen size and geometry, together with as much detail of the concrete mix and its mechanical properties as was available in the source.

The data sets have been grouped in the following order. First, the data sets for the same mixes obtained on specimens of identical span to depth ratio and width, $B$ (sets 1,2 and 3-5). These are followed with the data set 6 referring to the same mix as sets $3-5$ but on specimens with a larger span to depth ratio. The next three quartets of data sets (sets $7-10,11-14$ and 15-18) each refer to the same mix but for specimens with different span to depth ratios. These are followed by two quartets of data sets (sets 19-22, and 23-26) obtained on geometrically identical specimens but from mixes differing by water to cement ratio and texture of coarse aggregate.

Data sets 1 and 2 are rather special and very revealing. The $G_{f}(\alpha)$ value was calculated for small increments of crack extension ranging from $\alpha=0.295$ to $\alpha=0.908$ in set 1 and from $\alpha=0.375$ to 0.883 in set 2. The measured $G_{f}(\alpha)$ values are plotted in Figs 3 and 


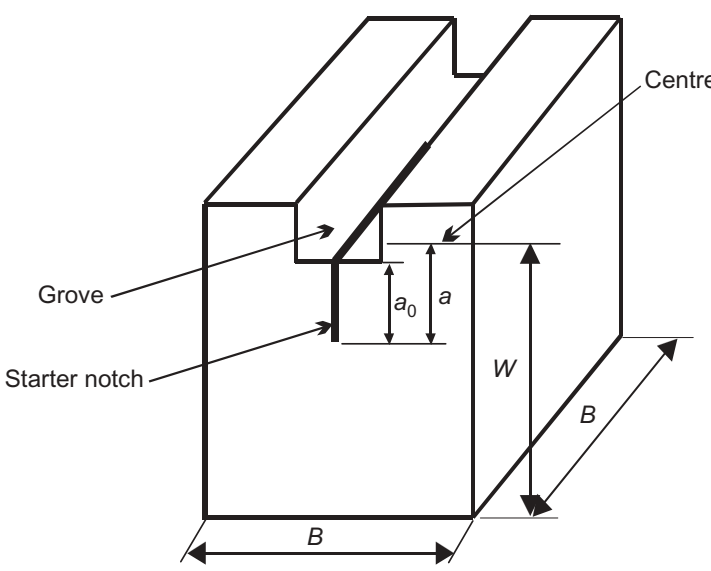

(a)

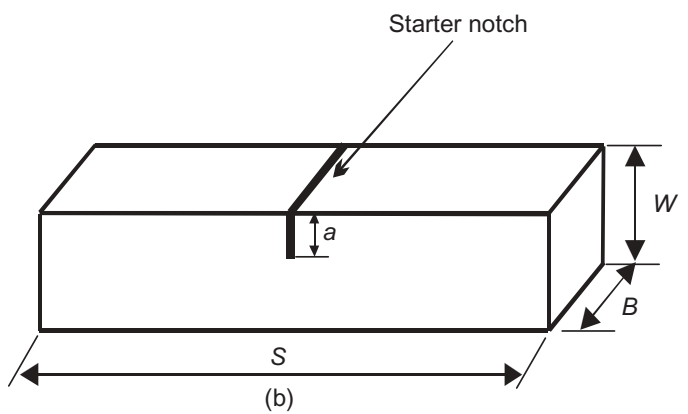

Fig. 2. Specimen shapes and dimensions: (a) Wedge splitting (WS) specimen; (b) Three point bend (TPB) specimen

4 against $\alpha$. The variation of $G_{f}(\alpha)$ with $\alpha$ is very similar to that assumed by $\mathrm{Hu}$ and Wittmann ${ }^{4}$ in the development of their model based on the effect of the free boundary on the fracture energy.

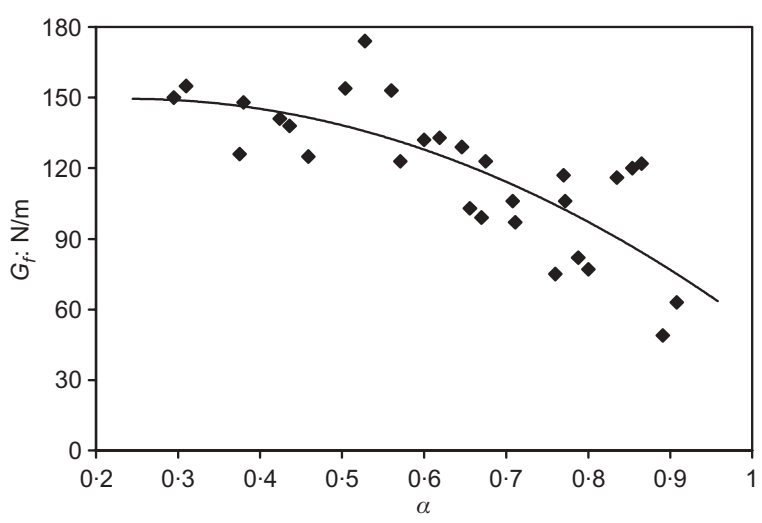

Fig. 3. Variation of $\mathrm{G}_{\mathrm{f}}(\alpha)$ with notch to depth ratio for data set 1 showing the best-fit curve

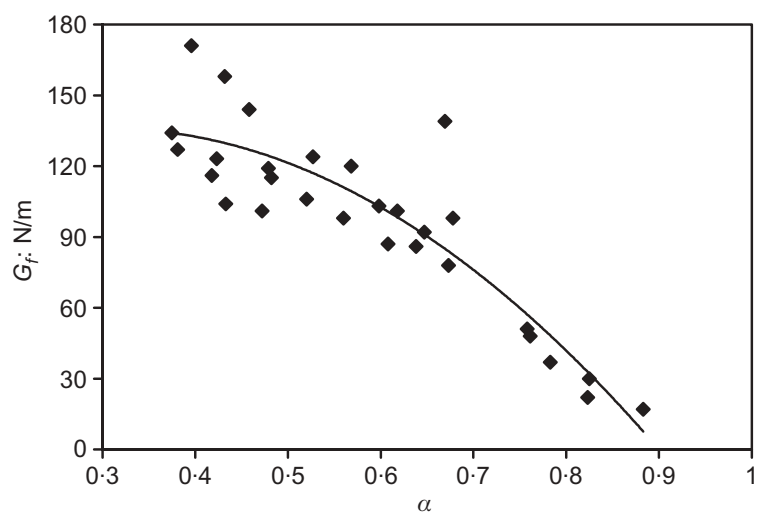

Fig. 4. The variation of $\mathrm{G}_{\mathrm{f}}(\alpha)$ with notch to depth ratio for data set 2 showing the best-fit curve
The measured values of $G_{f}(\alpha)$ in each data set have been fitted by a second order polynomial to reveal the trend as $\alpha$ increases. This trend is best captured by

$$
G_{f}^{*}(\alpha)=A_{0}+A_{1} \alpha+A_{2} \alpha^{2}
$$

A regression analysis was performed on the measured values of $G_{f}(\alpha)$ to determine the coefficients $A_{i}$ ( $i=$ $0,1,2)$ that best fit the data. Apart from data sets 1 and 2 in which there is a large scatter in the measured $G_{f}(\alpha)$ values (see Figs 3 and 4), the coefficient of determination $R^{2}$ value of all the data sets is close to 1 . This is not surprising since the data sets $3-26$ consist of 5 or 6 data points, each of which is in turn, the mean of between 3 and 11 test results, whereas sets 1 and 2 consist of greater number of individual test results. The values of $G_{f}(\alpha)$ resulting from the smoothing procedure are denoted $G_{f}^{*}(\alpha)$ and tabulated alongside $G_{f}(\alpha)$ in the Appendix. The result of the smoothing procedure is shown in Fig. 5 on three typical data sets. The $G_{f}^{*}(\alpha)$ values are used instead of $G_{f}(\alpha)$ in equation (1).

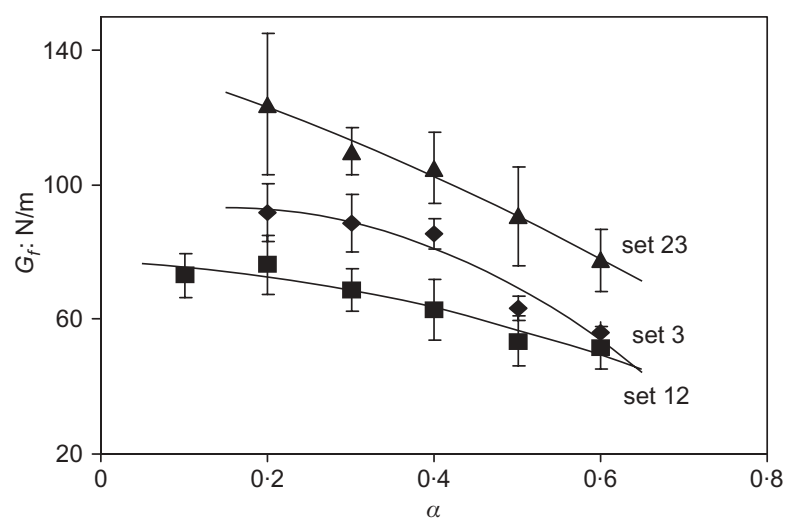

Fig. 5. Variation of $\mathrm{G}_{\mathrm{f}}(\alpha)$ with notch to depth ratio for data set 23 (top), set 3 (middle) and set 12 (bottom), showing the best-fit curves 


\section{Results and discussion}

Table 1 gives the value of the specific fracture energy $G_{F}$ of each set obtained by considering all notch to depth ratios and solving the overdetermined system of simultaneous equations (1) by a least squares method. The table also gives the value of $G_{F}$ of each data set obtained by considering only the smallest and the largest notch to depth ratios and solving the system of two equations (1) in two unknowns $G_{F}$ and $a_{l}$. A comparison of the two $G_{F}$ values so obtained for each concrete mix (i.e. each data set) clearly shows that the specific fracture energy $G_{F}$ can indeed be obtained from the mean $G_{f}^{*}(\alpha)$ values measured on a few specimens of the same overall dimensions and shape but with half of them containing a very shallow starter notch and the other half a deep notch. The difference in the value of $G_{F}$ should therefore only be due to the differences in the mix properties, i.e. water to cement ratio, maximum aggregate size and cement content. For a given mix, the $G_{F}$ value should be independent of the size of the specimen. This is confirmed by a comparison of $G_{F}$ values of data sets 1 and 2 , and of sets 3-5. The $G_{F}$ in each instance is nearly the same for the same mix although it has been obtained from tests on

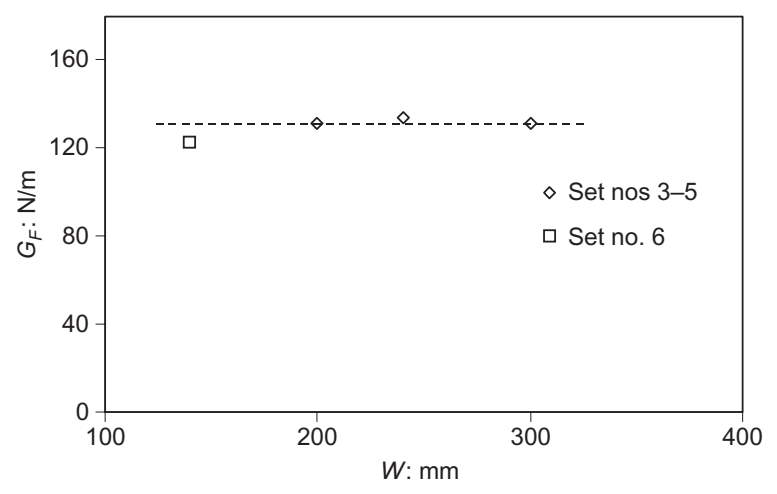

Fig. 6. $\mathrm{G}_{\mathrm{F}}$ of the concrete mix of sets 3-5 obtained from specimens of different depths but the same span to depth ratio. For comparison the slightly smaller $\mathrm{G}_{\mathrm{F}}$ of the same mix (set 6) obtained from specimens with larger span to depth is also included. This last value is closer to the true $\mathrm{G}_{\mathrm{F}}$ of the mix

specimens with different depths, $W$, but identical $B$ and span to depth ratio (Fig. 6).

A closer examination of the $G_{F}$ values (Table 1) also reveals that $G_{F}$ is indeed a constant for a given mix provided the specimens with different depths, $W$, have

Table 1. The specific fracture energy $\mathrm{G}_{\mathrm{F}}$ obtained from single specimen size and two extreme notch to depth ratios, compared with $\mathrm{G}_{\mathrm{F}}$ obtained using all notch to depth ratios. The span to depth ratio of the specimen and the maximum size of aggregate used in the mix allow comments to be made as to the true value of $\mathrm{G}_{\mathrm{F}}$ (last column)

\begin{tabular}{|c|c|c|c|c|c|c|c|}
\hline \multirow[b]{2}{*}{ Set no. } & \multirow[b]{2}{*}{$S / W$} & \multirow[b]{2}{*}{$d_{a}(\mathrm{~mm})$} & \multirow[b]{2}{*}{$\mathrm{w} / \mathrm{c}$ ratio } & \multirow[b]{2}{*}{$\begin{array}{l}\text { Aggr. } \\
\text { type }\end{array}$} & \multicolumn{2}{|c|}{$G_{F}: \mathrm{N} / \mathrm{m}$} & \multirow[b]{2}{*}{ Comments on $G_{F}$} \\
\hline & & & & & $\begin{array}{l}\text { All values of } \\
\qquad a / W\end{array}$ & $\begin{array}{l}\text { Extreme values } \\
\text { of } a / W\end{array}$ & \\
\hline 1 & $3 \cdot 75$ & 19 & $0 \cdot 50$ & & $160 \cdot 11$ & $160 \cdot 11$ & True $\mathrm{G}_{\mathrm{F}}<160.11 \mathrm{~N} / \mathrm{m}$ \\
\hline 2 & $3 \cdot 75$ & & & & $160 \cdot 90$ & $160 \cdot 90$ & \\
\hline 3 & $6 \cdot 00$ & & & & $135 \cdot 60$ & $131 \cdot 50$ & \\
\hline 4 & $6 \cdot 00$ & 20 & $0 \cdot 50$ & RRG & $133 \cdot 80$ & $133 \cdot 80$ & True $\mathrm{G}_{\mathrm{F}}<122.80 \mathrm{~N} / \mathrm{m}$ \\
\hline 5 & $6 \cdot 00$ & & & & $131 \cdot 70$ & $131 \cdot 70$ & \\
\hline 6 & $7 \cdot 14$ & & & & $122 \cdot 80$ & $122 \cdot 80$ & \\
\hline 7 & $3 \cdot 92$ & & & & $88 \cdot 30$ & $82 \cdot 90$ & \\
\hline 8 & $3 \cdot 13$ & 10 & $0 \cdot 50$ & RRG & $96 \cdot 90$ & $94 \cdot 40$ & True $\mathrm{G}_{\mathrm{F}} \approx 82.90 \mathrm{~N} / \mathrm{m}$ \\
\hline 9 & $2 \cdot 63$ & & & & $103 \cdot 90$ & $100 \cdot 30$ & \\
\hline 10 & 1.96 & & & & $123 \cdot 40$ & $119 \cdot 50$ & \\
\hline 11 & $6 \cdot 25$ & & & & $78 \cdot 20$ & $78 \cdot 20$ & \\
\hline 12 & $5 \cdot 26$ & 14 & $0 \cdot 50$ & RRG & $95 \cdot 80$ & $95 \cdot 80$ & True $\mathrm{G}_{\mathrm{F}}<78.20 \mathrm{~N} / \mathrm{m}$ \\
\hline 13 & $3 \cdot 92$ & & & & $121 \cdot 70$ & $121 \cdot 70$ & (see note in text about the \\
\hline 14 & $3 \cdot 15$ & & & & $145 \cdot 30$ & $141 \cdot 50$ & correctness of this value) \\
\hline 15 & $7 \cdot 89$ & & & & $94 \cdot 70$ & $92 \cdot 50$ & \\
\hline 16 & $5 \cdot 88$ & 20 & $0 \cdot 50$ & RRG & $109 \cdot 80$ & $107 \cdot 60$ & True $\mathrm{G}_{\mathrm{F}} \approx 92.50 \mathrm{~N} / \mathrm{m}$ \\
\hline 17 & $4 \cdot 72$ & & & & $137 \cdot 93$ & $135 \cdot 10$ & \\
\hline 18 & $3 \cdot 95$ & & & & $156 \cdot 10$ & $151 \cdot 60$ & \\
\hline 19 & $5 \cdot 88$ & 20 & $0 \cdot 50$ & RRG & $119 \cdot 80$ & $119 \cdot 80$ & True $\mathrm{G}_{\mathrm{F}}<119.80 \mathrm{~N} / \mathrm{m}$ \\
\hline 20 & $5 \cdot 88$ & 20 & $0 \cdot 55$ & RRG & $117 \cdot 80$ & $117 \cdot 80$ & True $\mathrm{G}_{\mathrm{F}}<117.90 \mathrm{~N} / \mathrm{m}$ \\
\hline 21 & $5 \cdot 88$ & 20 & $0 \cdot 60$ & RRG & $90 \cdot 40$ & $90 \cdot 40$ & True $\mathrm{G}_{\mathrm{F}}<90.40 \mathrm{~N} / \mathrm{m}$ \\
\hline 22 & $5 \cdot 88$ & 20 & $0 \cdot 65$ & RRG & $90 \cdot 10$ & $90 \cdot 10$ & True $\mathrm{G}_{\mathrm{F}}<90 \cdot 10 \mathrm{~N} / \mathrm{m}$ \\
\hline 23 & $5 \cdot 88$ & 20 & $0 \cdot 50$ & CRG & $167 \cdot 50$ & $167 \cdot 50$ & True $\mathrm{G}_{\mathrm{F}}<167.50 \mathrm{~N} / \mathrm{m}$ \\
\hline 24 & $5 \cdot 88$ & 20 & $0 \cdot 55$ & CRG & $153 \cdot 40$ & $153 \cdot 40$ & True $\mathrm{G}_{\mathrm{F}}<153.40 \mathrm{~N} / \mathrm{m}$ \\
\hline 25 & $5 \cdot 88$ & 20 & $0 \cdot 60$ & CRG & $145 \cdot 50$ & $145 \cdot 50$ & True $\mathrm{G}_{\mathrm{F}}<145.50 \mathrm{~N} / \mathrm{m}$ \\
\hline 26 & $5 \cdot 88$ & 20 & $0 \cdot 65$ & CRG & $100 \cdot 20$ & $100 \cdot 20$ & True $\mathrm{G}_{\mathrm{F}}<100 \cdot 20 \mathrm{~N} / \mathrm{m}$ \\
\hline
\end{tabular}

RRG rounded river gravel

CRG crushed river gravel 
the same span to depth ratio and the same thickness, $B$ (Fig. 2). These conditions are met by the two mixes from which the beams in data sets 1 and 2, and sets 3-5 are made. These conditions were also met by the TPB and WS specimens in the 10 data sets used by Abdalla and Karihaloo. ${ }^{11}$ In fact, it is a common practice in the testing of concrete for the specific fracture energy to use specimens of different depths, $W$, and notch to depth ratio, $a / W$, but having the same span to depth ratio (for TPB specimens) and the same thickness, $B$ (for TPB and WS specimens).

It is clear from the results in Table 1 that even for the same concrete mix, the value of $G_{F}$ varies with the span to depth ratio. This is seen from Fig. 7 which shows the data sets $7-10,11-14$ and $15 \cdot 18$. Each quartet of these data sets is for the same concrete mix

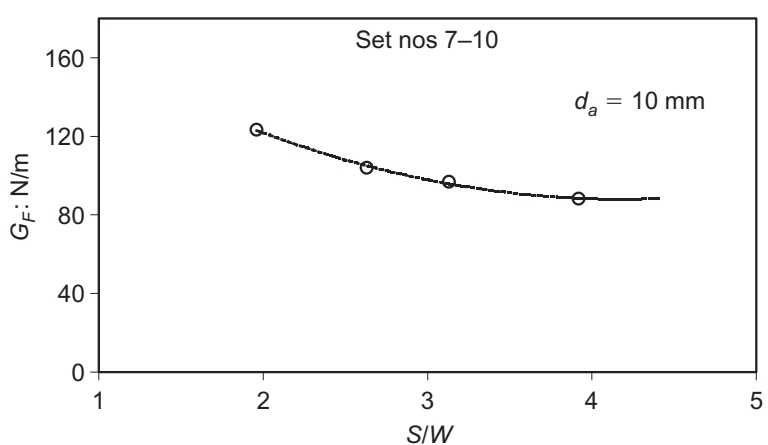

(a)

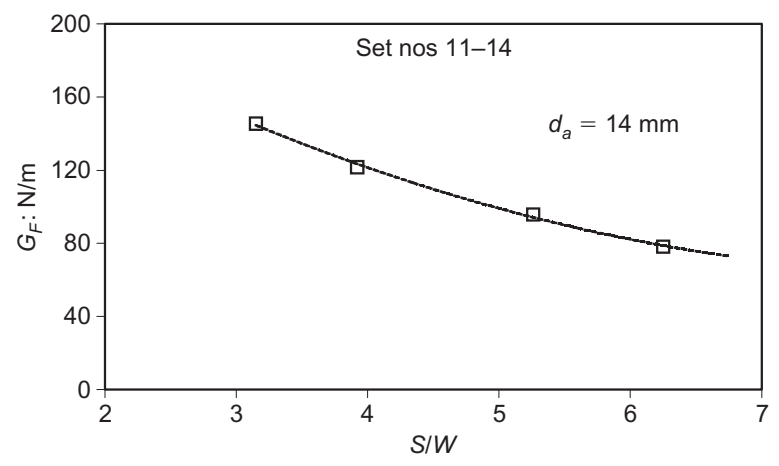

(b)

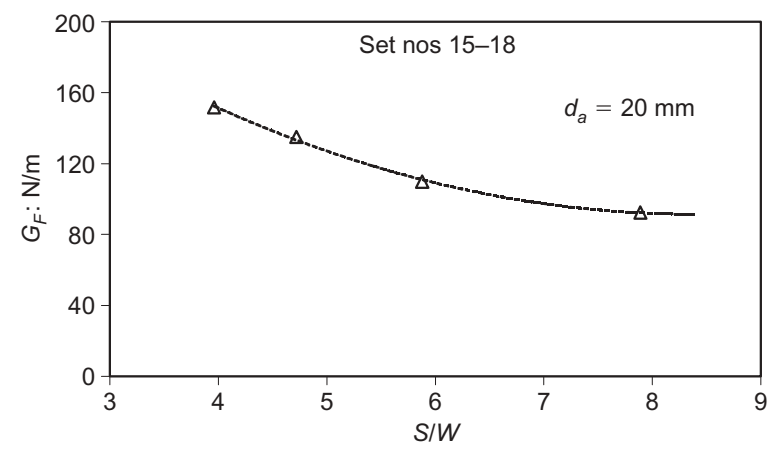

(c)

Fig. 7. Variation of $\mathrm{G}_{\mathrm{F}}$ with the span to depth ratio $\mathrm{S} / \mathrm{W}$ for mixes differing by the maximum size of coarse aggregates $\mathrm{d}_{\mathrm{a}}$ in the mix but the $G_{F}$ has been obtained from TPB specimens differing by the span to depth ratio.

$G_{F}$ decreases with an increase in span to depth ratio up to a value that depends only on the maximum size of the aggregate used in the mix. Beyond this value of the span to depth ratio, $G_{F}$ remains a constant. For the maximum size of aggregate $d_{a} \leqslant 10 \mathrm{~mm}$, this happens at a span to depth ratio of 4 , but for $10 \mathrm{~mm}<d_{a} \leqslant 20$ $\mathrm{mm}$ the ratio is closer to $7-8$. Thus, the true specific fracture energy $G_{F}$ of a concrete mix can only be obtained when the span to depth ratio of the TPB specimens is equal to, or greater than, 4 depending on the maximum size of the aggregates in the mix.

The results for the mix with $d_{a}=14 \mathrm{~mm}$ are rather odd. It is generally known that $G_{F}$ increases with an increase in $d_{a}$, as is also confirmed by the results for mixes with $d_{a}=10$ and $20 \mathrm{~mm}$ (sets 7-10 and 15-18). The expected result for mix with $d_{a}=14 \mathrm{~mm}$ is somewhere between that for mixes with $d_{a}=10$ and $20 \mathrm{~mm}$. This is not the case for sets 11-14 (Table 1), so that it is very likely that the minimum required span to depth ratio increases with increasing $d_{a}$ in the range $10 \mathrm{~mm}<d_{a} \leqslant 20 \mathrm{~mm}$, rather than being constant at $7-8$, as found above.

The minimum span to depth requirement was met by the specimens used by Abdalla and Karihaloo ${ }^{11}$ for mixes with $d_{a}=10 \mathrm{~mm}$. However, it is not met by some of the data sets used in the above re-evaluation.

The $S / W$ ratio of the specimens in data sets 1 and 2 is only 3.75 for a mix with $d_{a}=19 \mathrm{~mm}$, whereas it should be nearer 8 in order to obtain true $G_{F}$. Not surprisingly, the $G_{F}$ based on $S / W=3.75$ is about 160 $\mathrm{N} / \mathrm{m}$, whereas the true $G_{F}$ would be about $95 \mathrm{~N} / \mathrm{m}$, judging by Fig. 7 for $d_{a}=20 \mathrm{~mm}$.

Similarly, the $S / W$ ratio of the specimens in data sets $3-5$ is only 6 for a mix with $d_{a}=20 \mathrm{~mm}$. For the same mix, the $S / W$ ratio is $7 \cdot 14$ in data set 6 , which is closer to the required $S / W$ ratio for a mix with $d_{a}=20$ mm (Fig. 7). Therefore, the true $G_{F}$ of concrete mix of sets 3-6 is nearer to the value for set 6 rather than sets $3-5$, i.e. it is nearer to $120 \mathrm{~N} / \mathrm{m}$ rather than $130 \mathrm{~N} / \mathrm{m}$.

Likewise, the true $G_{F}$ value of concrete mix of data sets $7-10$ with $d_{a}=10 \mathrm{~mm}$ is that given by set 7 (see Fig. 7), that of the mix of data sets $11-14$ with $d_{a}=$ $14 \mathrm{~mm}$ is given by set 11 , and that of the mix of data sets $15-18$ with $d_{a}=20 \mathrm{~mm}$ by set 15 .

As is to be expected, the true $G_{F}$ of a concrete mix depends on mix parameters, namely water to cement ratio, cement content and the texture of coarse aggregates. For example, $G_{F}$ obtained from tests on specimens of identical geometry decreases with increasing water to cement ratio both when rounded (sets 19-22) and crushed river gravel $(23-26)$ is used in the mixes, as can be seen from Fig. 8. Note, however that the true $G_{F}$ of each of the mixes will be smaller than the value shown in Table 1 and Fig. 8 because the span to depth ratio of the specimens was only about 6 , whereas it should be in the range $7-8$ for $d_{a}=20 \mathrm{~mm}$. 


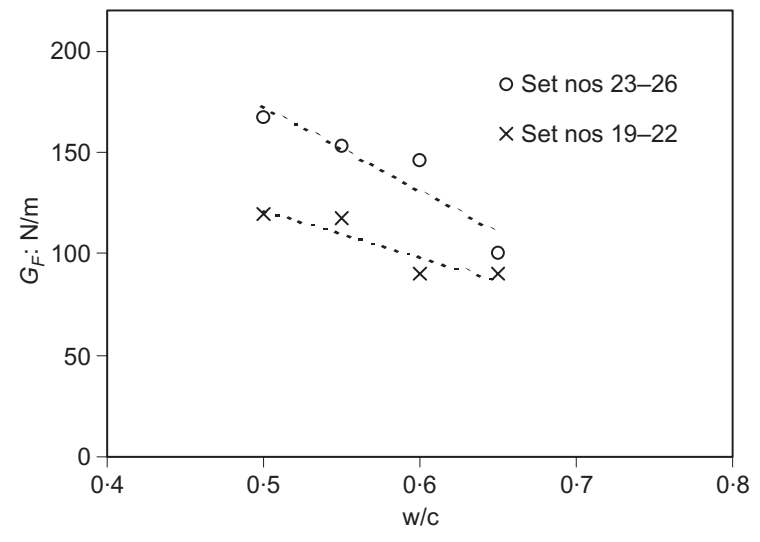

Fig. 8. Variation of $\mathrm{G}_{\mathrm{F}}$ with water to cement ratio and texture of coarse aggregate (o-crushed river gravel $C R G ; x$-rounded river gravel $R R G$ )

\section{Conclusion}

Based on the re-evaluation of 26 test data sets and on the 10 data sets of Abdalla and Karihaloo, ${ }^{11}$ covering concrete mixes with compressive strengths ranging from 24 to $100 \mathrm{MPa}$, the following conclusions can be drawn.

(a) The true specific fracture energy $G_{F}$ of a concrete mix can be determined by testing just a few (say, 10) specimens of the same shape and overall dimensions (depth $W$, thickness $B$, and span to depth ratio $S / W$ in the case of TPB). One half of the specimens must contain a very shallow starter notch $(a / W \leqslant 0 \cdot 1$ for TPB $)$ and the other half a deep starter notch $(a / W \geqslant 0.50$ for TPB $)$. The span to depth ratio of TPB specimens must be equal to, or greater than, 4 , if the maximum size of the aggregates in the mix $d_{a} \leqslant 10 \mathrm{~mm}$, or $7-8$ if 10 $<d_{a} \leqslant 20 \mathrm{~mm}$.

(b) The method described here greatly simplifies both the testing and the calculation procedures and gives the true specific fracture energy $G_{F}$ of the mix provided the restriction on the minimum $S / W$ ratio is met.

(c) If the span to depth ratio of TPB specimens is less than the above minimum value, then the predicted $G_{F}$ will be larger than the true value.

\section{Appendix}

The Appendix follows opposite 


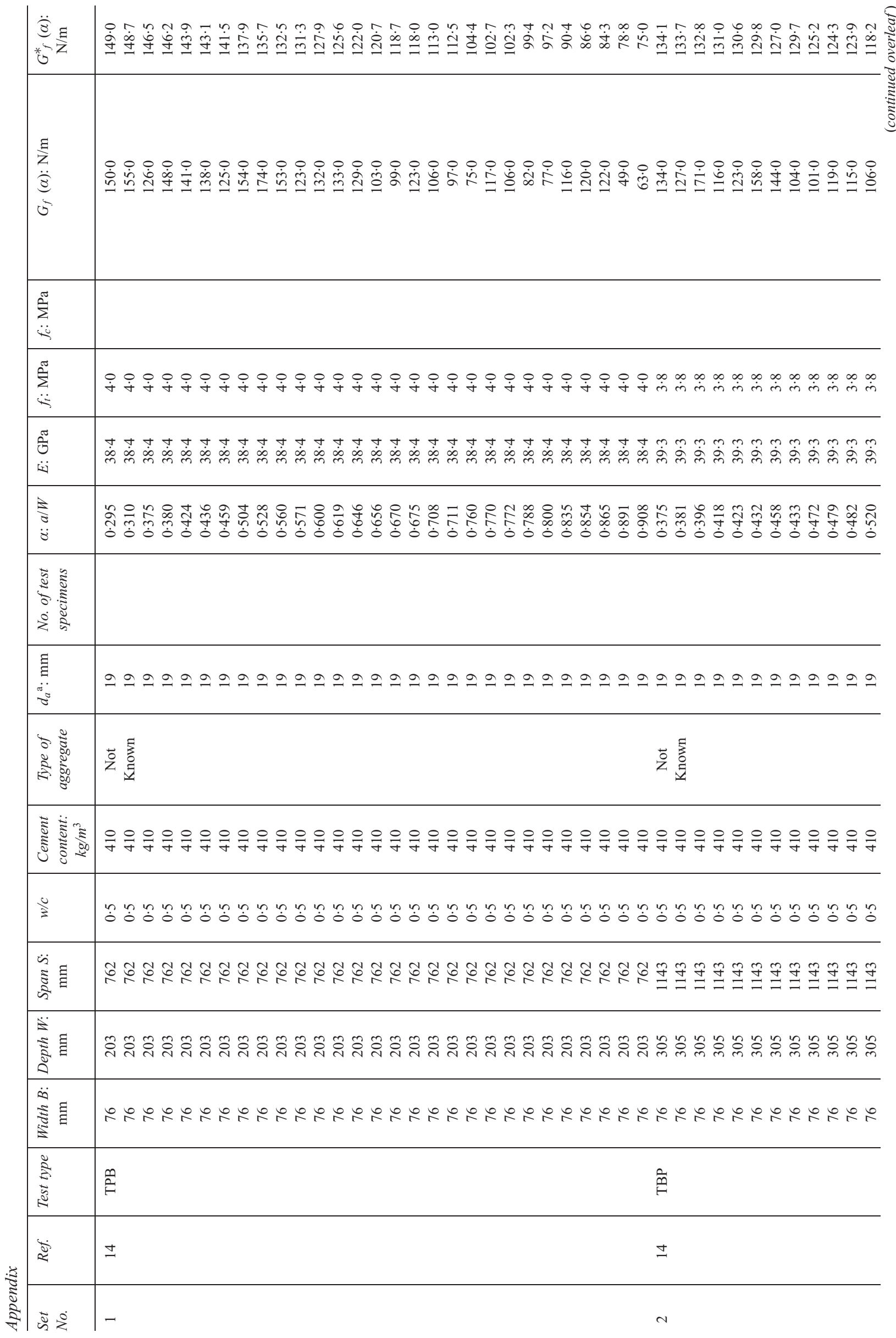




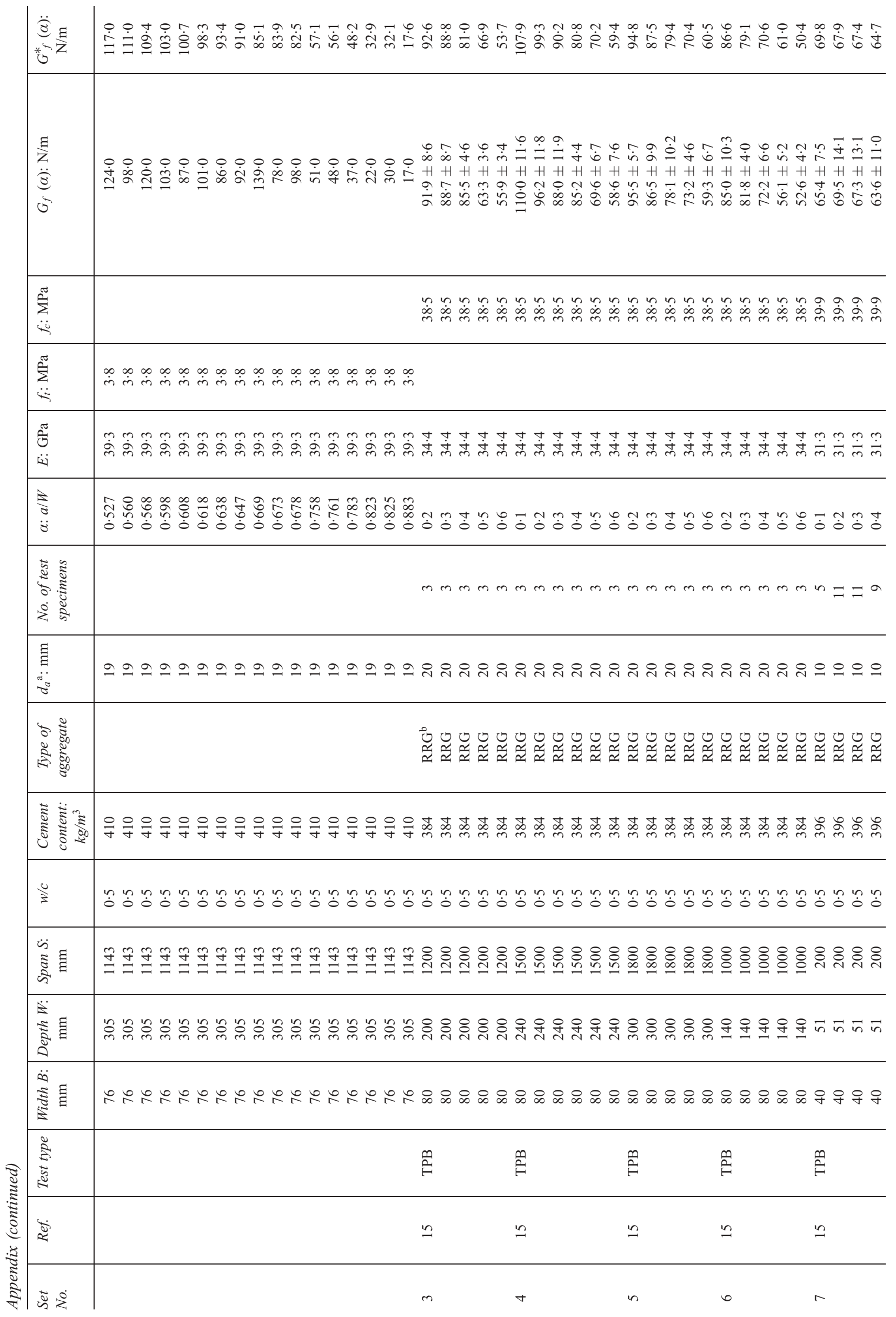




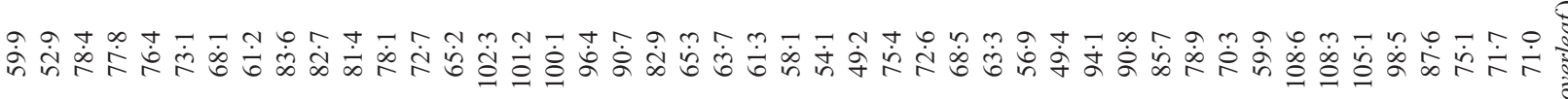

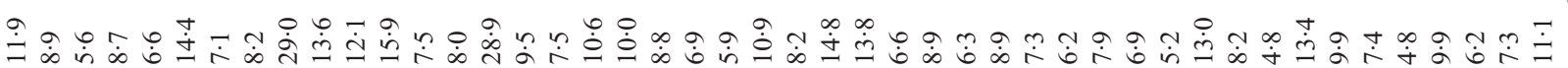
H H H H H H H H H H H H H H H H H H H H H H H H H H H H H H H H H H H H H H H H H H H H H H

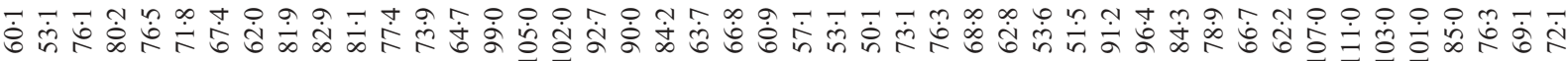

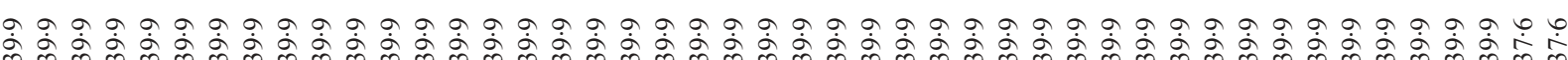

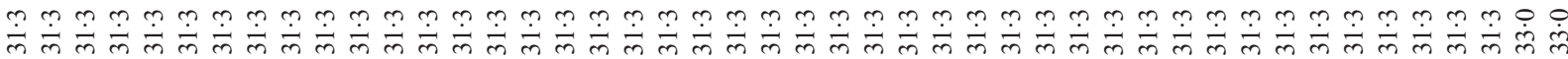

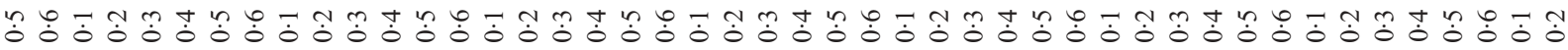

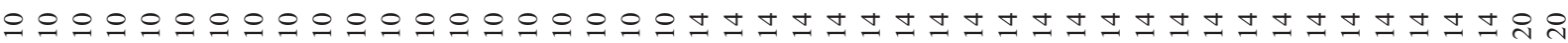

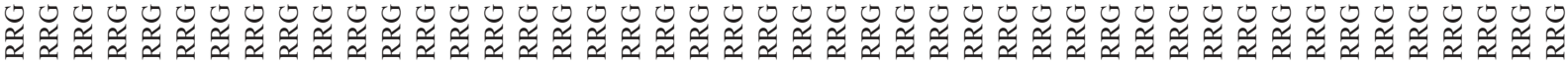

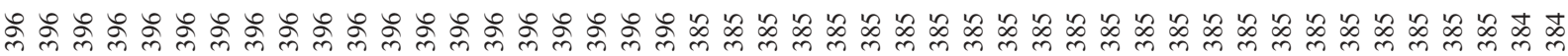
оำ

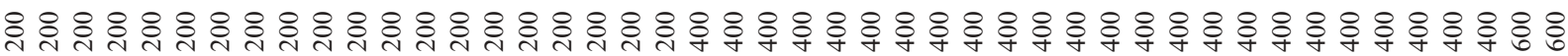
๘

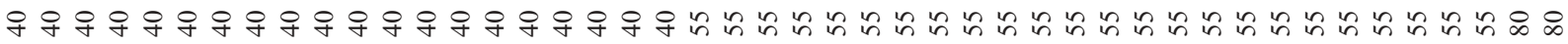

\begin{tabular}{|c|c|c|c|c|c|c|c|}
\hline$\stackrel{m}{\stackrel{m}{F}}$ & $\stackrel{m}{\stackrel{m}{G}}$ & $\stackrel{m}{\stackrel{\vartheta}{\Leftrightarrow}}$ & $\stackrel{n}{\hat{\beta}}$ & $\stackrel{m}{\stackrel{m}{\beta}}$ & 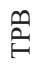 & 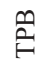 & $\stackrel{\infty}{\hat{F}}$ \\
\hline$\cong$ & $\cong$ & $\cong$ & $\cong$ & $\cong$ & $\cong$ & $\cong$ & $\cong$ \\
\hline$\infty$ & $a$ & $\circ$ & $=$ & $\simeq$ & $\stackrel{9}{2}$ & $\Xi$ & $\simeq$ \\
\hline
\end{tabular}




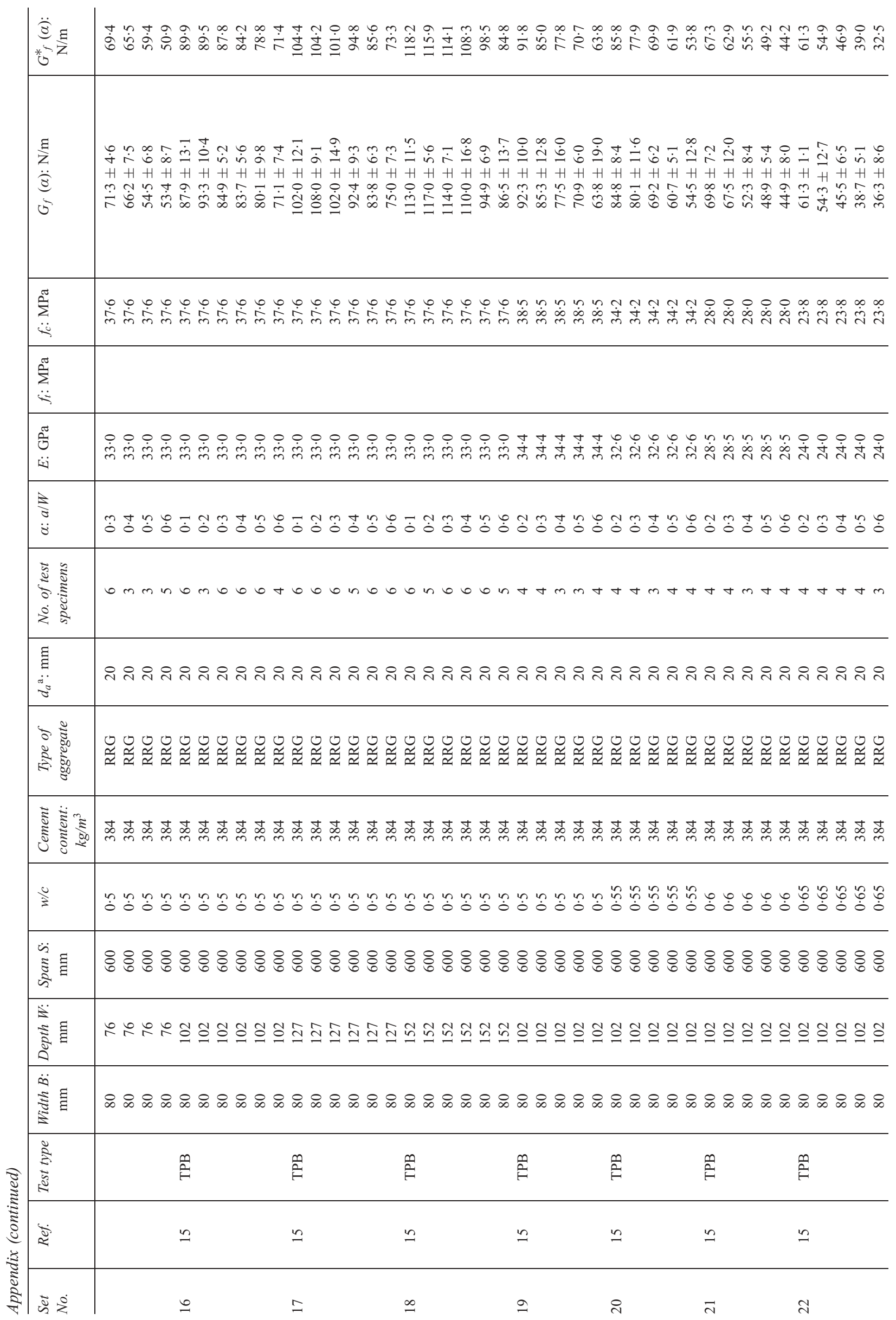




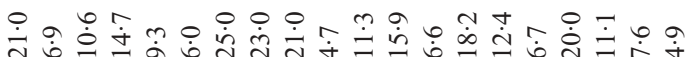
$H+H+H+H+H+H+H+H+H H+H+H+H$

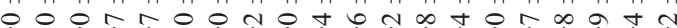

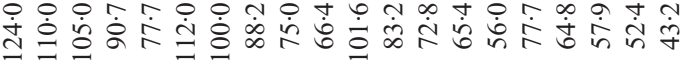

m

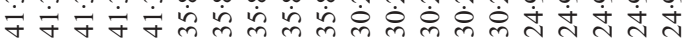

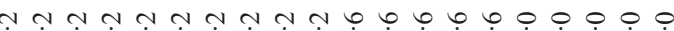

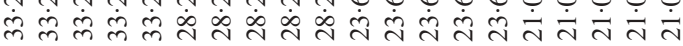

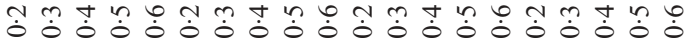

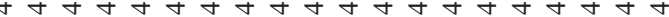

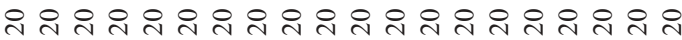

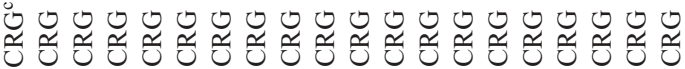

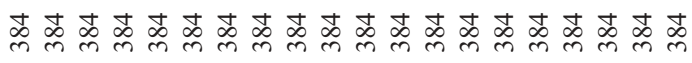

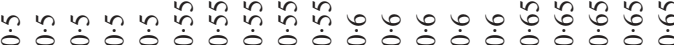

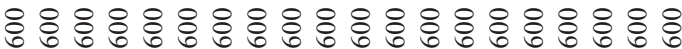

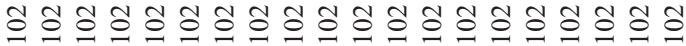

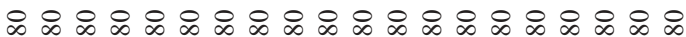

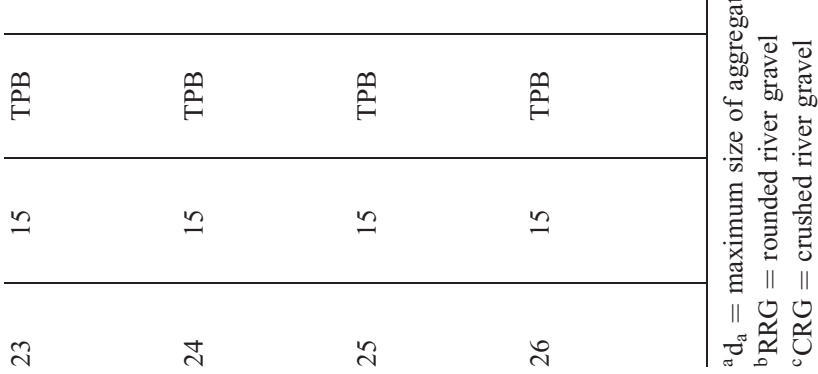

Magazine of Concrete Research, 2003, 55, No. 5

\section{References}

1. Karihaloo B. L. Fracture Mechanics and Structural Concrete, Addison Wesley Longman, UK, 1995.

2. Guinea G. V., Planas J. and Elices M. Measurement of the fracture energy using three-point bend tests: part 1-Influence of experimental procedures. Materials and Structures, 1992, 25, $212-218$.

3. Elices M., Guinea G. V. and Planas J. Measurement of the fracture energy using three-point bend tests: part 3-Influence of cutting the $P-\delta$ tail. Materials and Structures, 1992, 25, 327334.

4. Hu X. Z. and Wittmann F. H. Fracture energy and fracture process zone. Materials and Structures, 1992, 25, 319-326.

5. Duan K., Hu X. Z. and Wittmann F. H. Boundary effect on concrete fracture induced by non-constant fracture energy distribution, in Fracture Mechanics of Concrete Structures (R. de Borst, J. Mazars, G. Pijaudier-Cabot and J. G. M. Van Mier (Eds)), Proc FRAMCOS-4, Balkema, Rotterdam, 2001, pp. 4955.

6. Duan K., Hu X. Z. and Wittmann F. H. Boundary effect on concrete fracture and non-constant fracture energy distribution. Engineering Fracture Mechanics, 2003, 70, in press.

7. HU X. Z. and Wittmann F. H. Size effect on toughness induced by crack close to free surface. Engineering Fracture Mechanics, 2000, 65, 209-211.

8. Nallathambi P., Karihaloo B. L. and Heaton, B. S. Effect of specimen and crack size, water/cement ratio and coarse aggregate texture upon fracture toughness of concrete. Magazine of Concrete Research, 1984, 36, 227-236.

9. Nallathambi P., Karihaloo B. L. and Heaton B. S. Various size effects in fracture of concrete. Cement and Concrete Research, 1985, 15, 117-121.

10. Nallathambi P. and Karihaloo B. L. Determination of the specimen size independent fracture toughness of plain concrete. Magazine of Concrete Research, 1986, 38, 67-76.

11. Abdalla H. M. and Karihaloo B. L. Determination of sizeindependent specific fracture energy of concrete from three-point bend and wedge splitting tests. Magazine of Concrete Research, 2003, 55, 133-141.

12. RILEM Committee FMC 50. Determination of the fracture energy of mortar and concrete by means of the three-point bend tests on notched beams. Materials and Structures, 1985, 18, $285-290$.

13. Hillerborg, A. Analysis of one single crack, in Fracture Mechanics of Concrete, (F. H. Wittmann (Ed.)), Elsevier, Amsterdam, 1983, pp. 223-249.

14. Refai M. E. and Swartz S. E. Fracture behaviour of concrete beams in bending considering the influence of size effects, Report No. 190, Engineering Experimental Station, Kansas State University, 1987.

15. Nallathambi P. Fracture Behaviour of Plain Concrete. PhD thesis, University of Newcastle, NSW, 1986.

Discussion contributions on this paper should reach the editor by 1 April 2004 